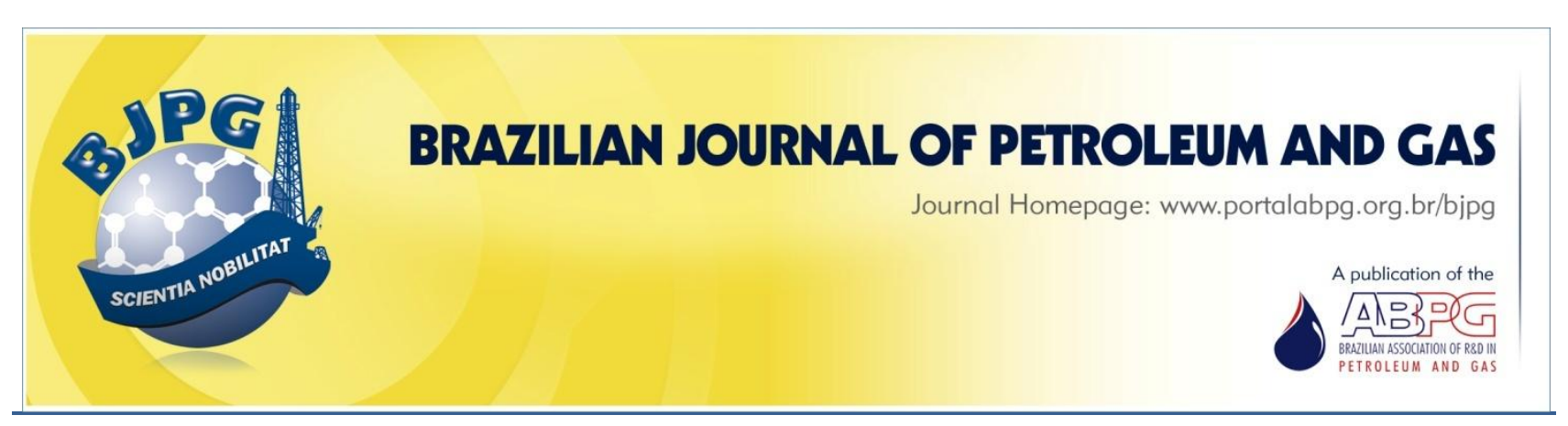

\title{
INTEGRATED EVALUATION OF CEMENT AND KICK SCENARIOS IN OIL WELL DESIGN
}

\author{
${ }^{\text {a }}$ Melo, J. M. F. ${ }^{1}$; ${ }^{\text {T }}$ Tenório, J. K. F.; ${ }^{a}$ Oliveira, A. G. C., ${ }^{a}$ Santos, J. P. L. \\ ${ }^{\mathrm{a}}$ Federal University of Alagoas, Graduate Program in Petroleum Engineering, Maceió - AL - Brazil
}

Received: 17.07.2019 / Revised: 31.08.2019 / Accepted: 01.09.2019 / Published on line: 08.10.2019

\begin{abstract}
The present work aims to develop a case study using the casing well interface (CWELL), developed by the Federal University of Alagoas, Brazil. Considering the well critical environment during the gas kick along with wait on cement (WOC) test and cement displacement, we sought to observe the behavior of different casing pipes regarding the stress submitted. The case study analyzes an offshore vertical well, with a water depth of 1574 meters. The well was subjected to a kick of $50 \mathrm{bbl}$ and with an inflow gradient of $2.0 \mathrm{lb} / \mathrm{gal}$. Triaxial loads were obtained through the von-Mises and American Petroleum Institute (API) envelopes, which can be used to analyze the integrity of the tubes. Through the analysis between the resistances returned by Petroleum Engineering Applications System (SAEP), it is possible to verify the possibility of failure of the tubes for each project scenario. This analysis is important for determining the sizing of the columns to obtain the best performance of the structures.
\end{abstract}

\section{KEYWORDS}

casing; resistances; CWELL; gas kick; integrity

\footnotetext{
${ }^{1}$ To whom all correspondence should be addressed.

Address: Federal University of Alagoas, Graduate Program in Petroleum Engineering, Av. Lourival Melo Mota, s/n, Maceió - AL Brazil.

ZIP Code: 57072-900 | e-mail: jennifer.melo@ctec.ufal.br

doi:10.5419/bjpg2019-0019
} 


\section{INTRODUCTION}

Risks associated with the exploration and production of petroleum have increased the efforts to ensure wells integrity. The loss in market value of the British Petroleum Company (BP) after the Macondo blowout demonstrates the material losses an accident can cause during well construction activities. (Mendes et al., 2016). Moreover, the Brazilian National Petroleum, Gas, and Biofuels Agency (ANP), in 2017, reported that an explosion on a drilling rig had led to human losses, which highlights the complexity of oil well drilling operations and reinforces that ensuring safety is a crucial point in such activities.

A significant amount of time is spent on drilling operations. These operations involve a sequence of manual and semi-automated processes performed simultaneously to deliver results as safely and efficiently as possible (Baker \& Ferraioli, 2018). That said, this step is accomplished using a rotary probe, where the rocks are drilled through the rotation, and weight is applied onto the bit, which is located at the end of the drilling string. The drilling column is one of the most important components of the drilling rig, and it is composed of drill pipes, drill collars, and heavy weight pipes (Thomas, 2004).

After the drilling stage, the casing is installed. It consists of a coupling of special steel pipes of the same external diameter. Its main function is to protect the walls of the well and to avoid the influx of fluid from the formation, the invasion and loss of fluid from the well to the formation, guaranteeing well security in the later stages (Costa, 2016).

Casing columns in oil wells are submitted, necessarily, to a combined state of stress. These stresses can be tensile or compressive with internal or external pressure. They are responsible for representing the physical situation closest to reality. In this way, you can refer to the combined state as triaxial efforts (Correia \& Santos, 2017).

For Thomas (2004), the casing is divided into categories according to their purposes. The conductor casing is the first one to be settled in the well, at a depth of 10 to 100 meters, and its main function is to isolate unconsolidated surface areas. The surface casing, installed after the conductor, aims to isolate the poorly consolidated surface areas, to protect freshwater areas, and to serve as a basis for blow out preventer (BOP) and subsequent casing.

The intermediate casing's main function is to protect the areas at risk of loss of circulation and to isolate abnormally pressurized areas. It is positioned between the surface and the production casing. The production casing, on the other hand, is adjacent to possible production zones, harboring the production column and allowing the conduction of hydrocarbons to the surface (Thomas, 2004).

After the settlement of each types of casing described above, there is the cementing stage. The purpose of this operation is to provide a continuous impermeable hydraulic seal in the annulus, preventing any uncontrolled flow of reservoir fluids behind the casing. (Pelipenko \& Frigaard, 2004). It is one of the most important phases of the oil well construction process. The success of this operation is vital in determining the well's future productive life and the eventual return on investment (Thompson \& Callison, 1959). However, as the last step in well construction, cementing sometimes does not receive the attention it deserves.

The effects of a bad cement job are remedial jobs and environmental and safety concerns (Holt et al., 2013). Its purpose is to protect the metallic casing installed in the well, preventing the movement of the fluid through the annular space, as well as stopping the migration of the fluid to possible fractures in the formation. It is also used to close part of an abandoned well (Bourgoyne Jr., 1991). Thus, cementing is a key component that affects well life not only during the production phase, but also during abandonment (Rogers \& Heathman, 2005).

A number of problem cases are reported during the drilling phase. These issues involve closing wells, trapping drillstrings, and creating mechanical stops (Salmazo et al., 2013). In this sense, the success of the cementation is dictated by many factors, among them, the efficiency in the displacement of the cement paste, which requires mutual interactions of drilling fluid, spacers, and cement paste in the annular space. It is known that there are many causes for cement paste displacement problems and failures, including poorly conditioned wells, inadequate displacement flow rates, insufficient casing centering, and 
viscosity difference between mud-spacer-cement, which leads to interface instabilities (Enayatpour \& van Oort, 2017).

Previous studies have shown that low strength cements are not able to support the casing in oil wells. The cement resisting capacity is generally evaluated at the bottom of the well, where the pressure conditions are measured and the waitingon-cement test occurs (WOC) (Bearden \& Lane, 1961). Among the most critical scenarios considered in the industry, is the pressure test after cement hardening, which is a good indicator of failure in cementation (Vitorino et al., 2018).

It is also important to emphasize that, due to the lower density of the gas, a kick usually causes high pressure in the annular region. An expansion of the gas occurs when it reaches the surface, creating instability in the flow pattern of the drilling fluid due to turbulence caused by the mixture of drilling fluid and gas kick. (Oliveira, 2016).

The casing column should be sized and designed to resist the application of tension, internal pressure stresses, bending, and collapsing. In this context, the present work aims to develop a case study using the casing well interface (CWELL), developed by the Federal University of Alagoas, Brazil. Considering the well critical environment during the gas kick along with WOC test and cement displacement, it is desired to observe the behavior of different casing pipes when submitted to stress.

\section{MATERIALS AND METHODS}

CWELL is part of the Petroleum Engineering Applications System (SAEP), a multidisciplinary environment developed by the Federal University of Alagoas with the objective of performing applications for projects of casing columns, thus, allowing an analysis of the stability and integrity of the various phases of a well (Costa, 2016).

It is known that the main purpose of design standards is to ensure the quality of structures which are based on the mechanical strength criteria. Therefore, CWELL makes use of API ISO 10400 (2007) standards to obtain the results.

For the sizing of the casing columns, it is necessary to consider the minimum strength of the pipes to support the tension forces, internal pressure, collapsing, and bending; in addition to foreseeing possible operating problems, such as kick. The weight of the column itself triggers tensile stress, since the drill pipe located closest to the surface supports the entire weight of the column. Equation 1 expresses tensile strength (Silva, 2017).

The maximum strength to internal pressure is reached when the acting stress reaches the yield limit. The American Petroleum Institute (API) allows the thickness of new drill pipes to vary up to $12.5 \%$, with the internal pressure strength equation shown in Equation 2. The collapse is the result of a pressure difference; the external pressure is higher than the internal one. API TR 5C3 (2008) defines four collapse regimes: flow, plastic, transition, and elastic.

Thus, the calculation of the collapse strength depends on the type of collapse regime to which the drill pipe is subjected, which is identified from the ratio diameter and thickness of the pipe. The collapse strength is shown in Equations 3, 4, 5, and 6 , respectively, as previously mentioned (Silva, 2017).

$R_{t}=Y_{p} A_{t}$

$R_{p i}=\frac{(0.875) 2 t Y_{p}}{O D}$

$R_{y p}=2 Y_{p}\left[\frac{\left(\frac{D}{t}\right)-1}{\left(\frac{D}{t}\right)^{2}}\right]$

$R_{p p}=Y_{p}\left[\frac{A}{\frac{D}{t}}-B\right]-C$

$R_{t}=Y_{p}\left[\frac{F}{\frac{D}{t}}-G\right]$

$$
R_{e}=\frac{46.95 \times 10^{6}}{D / t[D / t-1]^{2}}
$$


where $Y_{p}$ represents the yield stress, $A_{t}$ is the cross-sectional area, $D$ is the diameter, and $t$ is the thickness.

Equations 7, 8, 9, 10, and 11 are used to calculate the constants present in the collapse strength equations.

$$
\begin{aligned}
A= & 2.8762+0.10679 \times 10^{-5} Y_{p}+ \\
& +0.21301 \times 10^{-10} Y_{p}^{2}-0.53132 \times 10^{-16} Y_{p}^{3} \\
B & =0.026233+0.50609 \times 10^{-6} Y_{p} \\
C & =-465.93+0.030867 Y_{p}- \\
- & 0.10483 \times 10^{-7} Y_{p}^{2}+0.36989 \times 10^{-13} Y_{p}^{3} \\
F= & \left.\frac{46.95 \times 10^{6}\left[\frac{3 B / A}{2+(B / A)}\right]^{3}}{Y_{p}\left[\frac{3 B / A}{2+(B / A)}-(B / A)\right] x\left[1-\frac{3 B}{A}\right.}\right]^{2} \\
G= & F\left(\frac{B}{A}\right) \\
&
\end{aligned}
$$

The resistances are compared to the loads submitted to the structure studied. If the load is greater than the value supported by the column, it can be an indicator of failure, lowering the credibility of its functions. In addition to uniaxial and biaxial efforts, triaxial results are a way to make the analysis even more discerning, which can be performed through API and von-Mises envelopes, as shown in Figure 1 (Costa, 2016).

According to Correia and Santos (2017), the envelopes are oriented through the ellipse of von Misses voltages and the API envelope, which is constructed based on safety limits. A combination of loads imposed on the structure outside the two envelopes indicates that it is not possible to guarantee that the pipe did not flow (Failure in Service Limit State -Plastic Deformation).

The von-Mises Plasticity criterion indicates that the following condition must be taken $\sigma_{V M E} \leq$ $Y_{p} \sigma_{V M E} \leq Y_{p}$, in which $\sigma_{V M E}$ is given by Equation 12 (Costa, 2016).

$$
\begin{aligned}
& \sigma_{V M E}= \\
& =\frac{1}{\sqrt{2}} \sqrt{\left(\sigma_{z}-\sigma_{h}\right)^{2}+\left(\sigma_{h}-\sigma_{r}\right)^{2}+\left(\sigma_{r}-\sigma_{z}\right)^{2}+6 \tau_{h a}} \\
& \geq Y_{p}
\end{aligned}
$$

Where $\sigma_{z}$ is the total axial stress (psi) and $\sigma_{V M E}$ is the equivalent triaxial voltage of Henky-von Mises (psi).

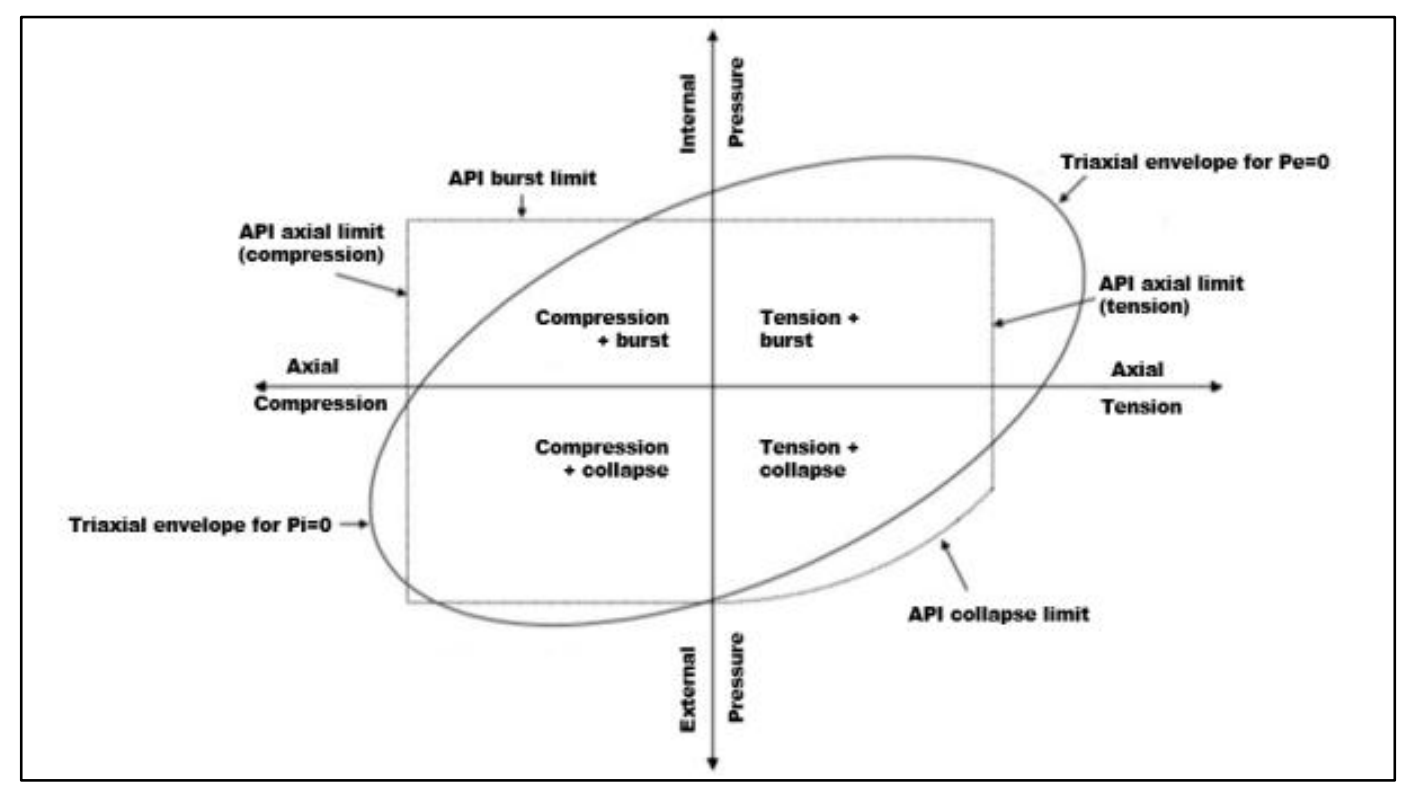

Figure 1. Ellipse of triaxial loads for casing pipes (Costa, 2016). 
According to Adams (1985), common problems considered in the casing design are kicks, circulation losses, column entrapment, and tube wear. Thus, in addition to evaluating these casing problems, it is important to perform a simultaneous analysis with the cementation step, studying cement displacement and WOC scenarios.

\section{RESULTS E DISCUSSIONS}

A casing analysis is performed on CWELL providing, for each well phase, input data (diameter, drilling fluid weight, and type of coating, among others).

It also considers critical internal pressure scenarios gas kick in phase 3 (more critical case than liquid kick) and complete well by gas in all three phases.

The case studied is an offshore vertical well, with a water depth of 1574 meters. The well is subjected to a kick of $50 \mathrm{bbl}$ and has an inflow gradient of $2.0 \mathrm{lb} / \mathrm{gal}$.

Triaxial loads were obtained through von-Mises and API envelopes, which can be used to analyze the integrity of the tubes.

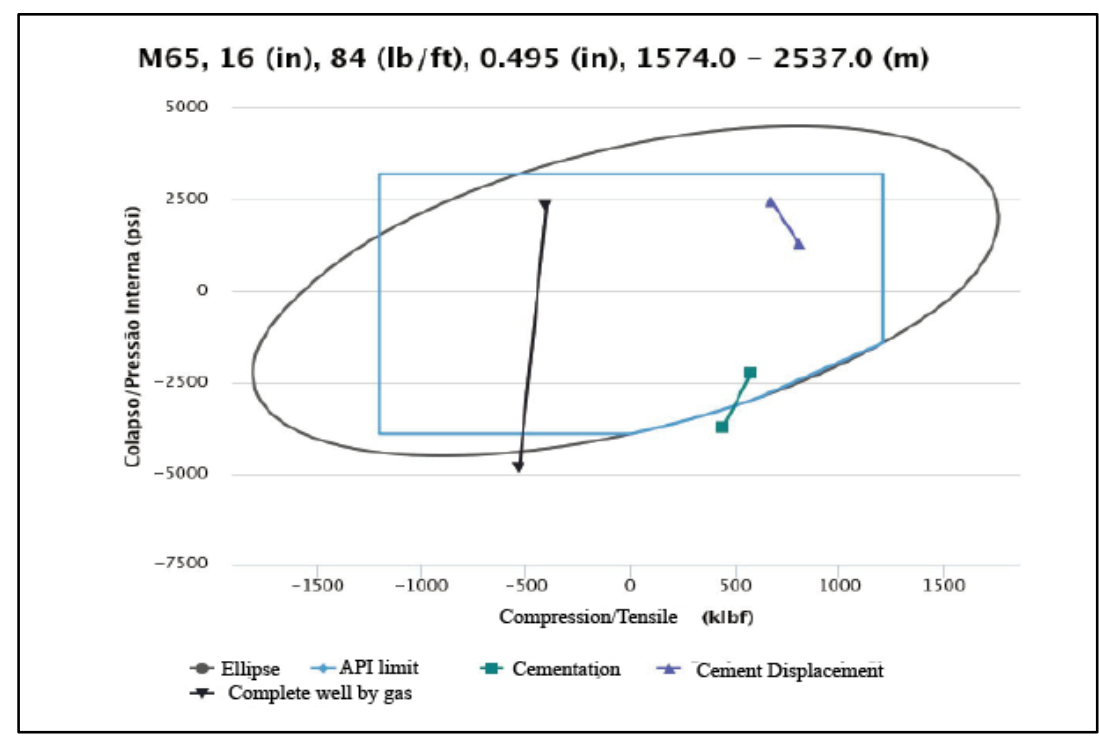

Figure 2. Triaxial results for the case of analysis with M65 in phase 2.

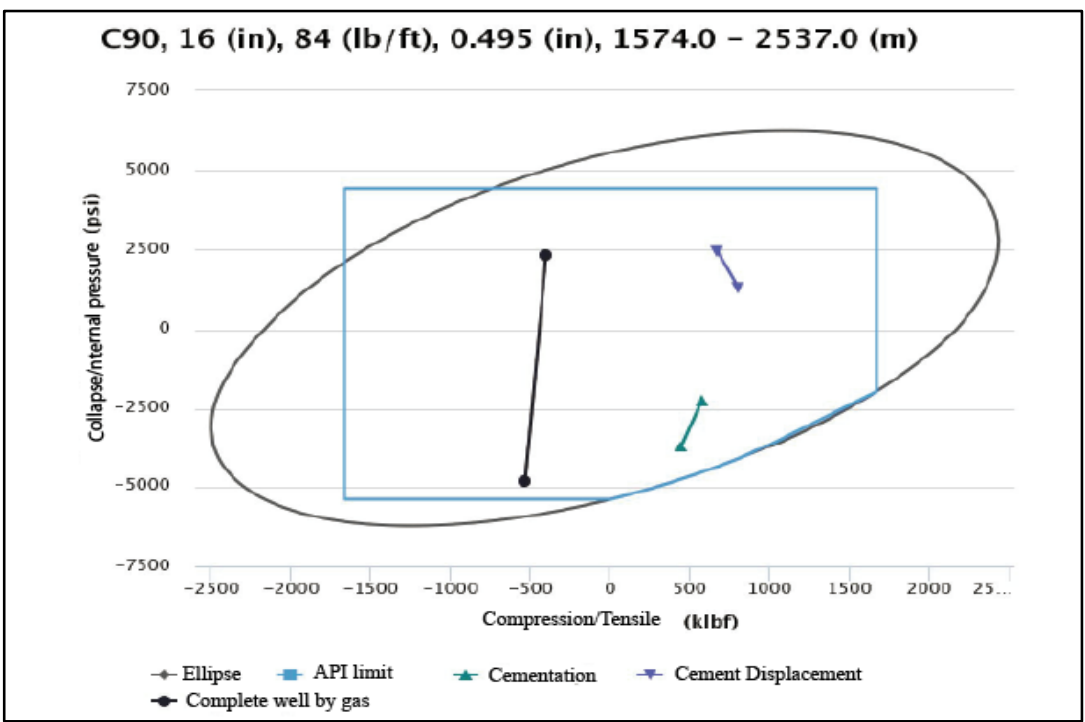

Figure 3. Triaxial results for the C90 analysis case in phase 2. 
Figure 2 shows that the chosen tube does not support the stresses imposed on it, violating the triaxial envelope. It is possible to observe that for the cases of complete gas well and cementing, the scenarios are not within von Misses and API envelopes.

Thus, by analyzing the use of an M65 steel casing, the need to increase the strength of the tube was observed, using a pipe of class C90, as shown in Figure 3.

When analyzing Figure 4, one can notice that the maximum tension to which the tube is submitted is lower than its tensile strength, ensuring that there is no failure by traction. The same behavior can be observed for the burst scenario, shown in Figure 5.
Analyzing the results obtained in phase 3, corresponding to the productor casing, a L80 tube was chosen, for its behavior did not correspond to the desired one, failing due to the critical gas kick scenario.

Since it the scenario ensured the integrity of the well, for the loads did not exceed von Misses and API envelopes, the mechanical strengths of the casings were analyzed to the requesting forces, shown in Table 1.

In a similar way to what was analyzed in phase 2 , it was possible to observe the need to increase the resistance of the tube in question (Figure 6). This is necessary since some of the scenarios under analysis go beyond the API and von Misses envelopes.

Table 1. Uniaxial strength for C90 investment column.

Phase 2

\begin{tabular}{cc}
\hline Tensile resistance $(\mathrm{klbf})$ & 2170.05 \\
Burst strength resistance $(\mathrm{psi})$ & 4872.66 \\
Collapse strength resistance (psi) & 1480.43 \\
\hline
\end{tabular}

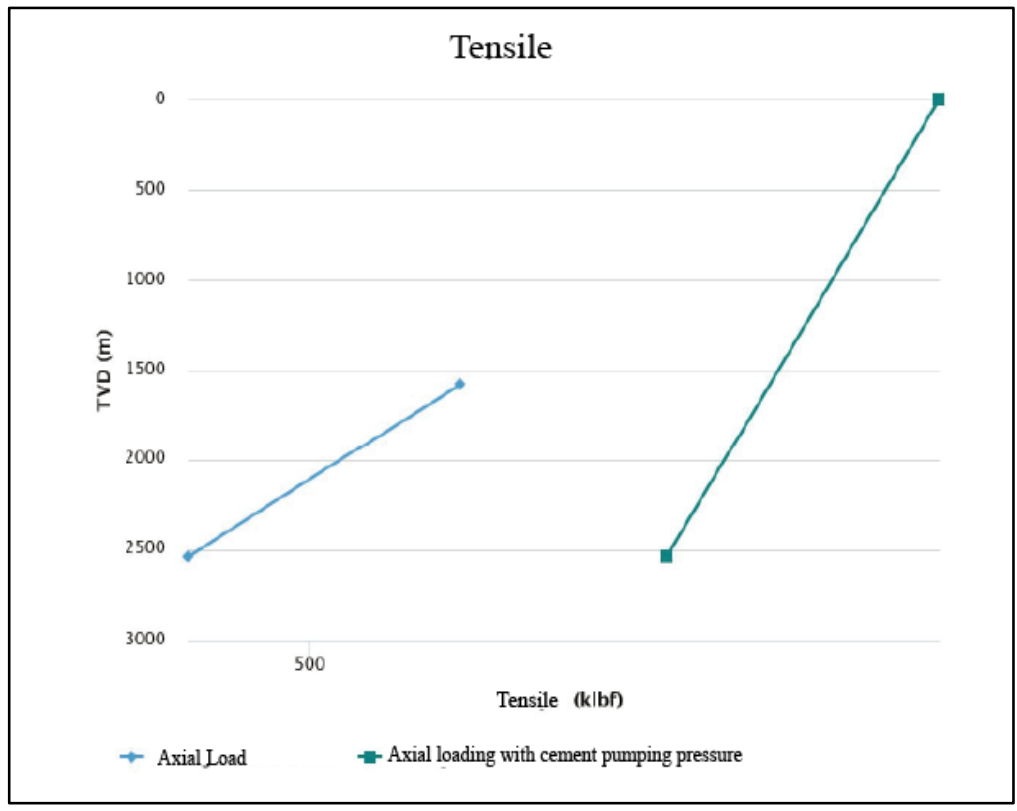

Figure 4. Axial loading in phase 2 for a C90 pipe. 


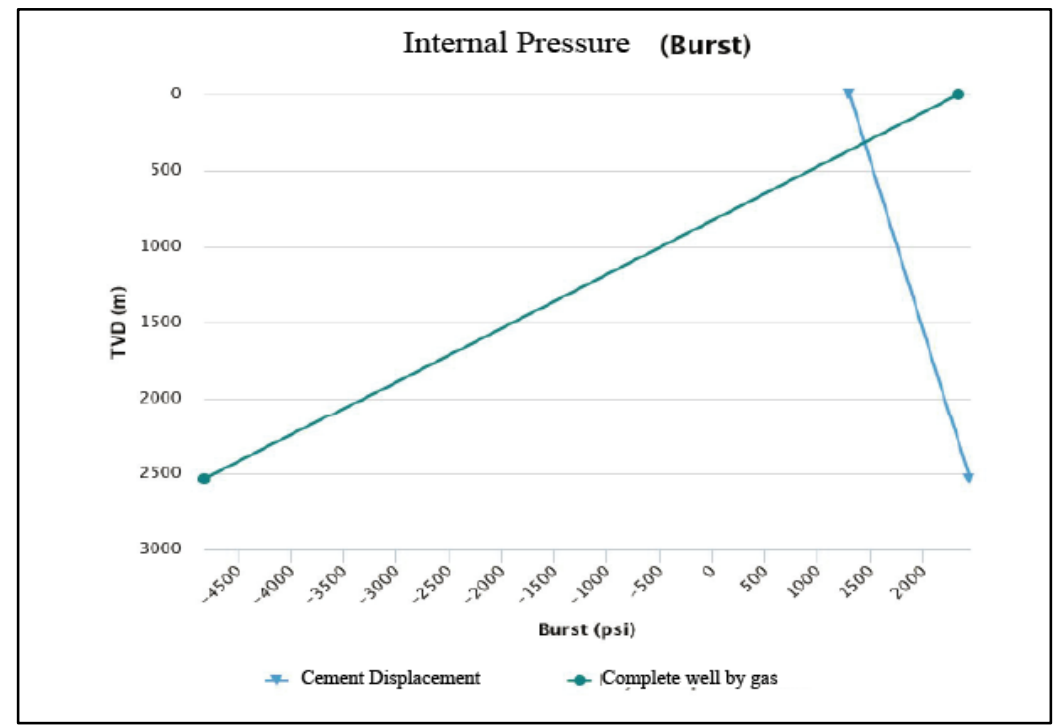

Figure 5. Internal Pressure Charging on Phase 2 for V150C90.

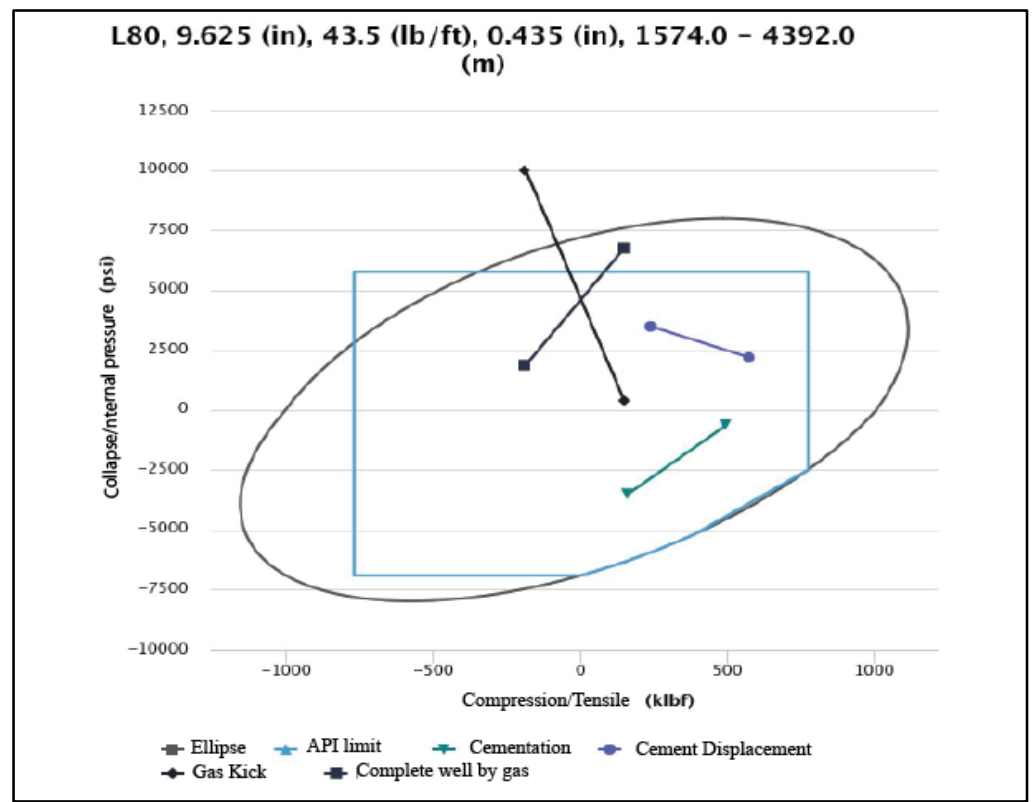

Figure 6. Triaxial results for the L80 phase 3 analysis case.

Therefore, analyzing the Gas Kick scenario, for instance, the need for a greater resistance is notorious, choosing the V150 pipe (Figure 7).
Thus, the results of the mechanical strength of the casings to the internal forces were obtained at the requesting stresses and were presented in Table 2.

Table 2. Uniaxial Resistances for V150 investment column.

Phase 3

Tensile resistance ( $\mathrm{klbf}$ ) 
V150, 9.625 (in), 43.5 (lb/ft), 0.435 (in), $1574.0-4392.0$

(m)

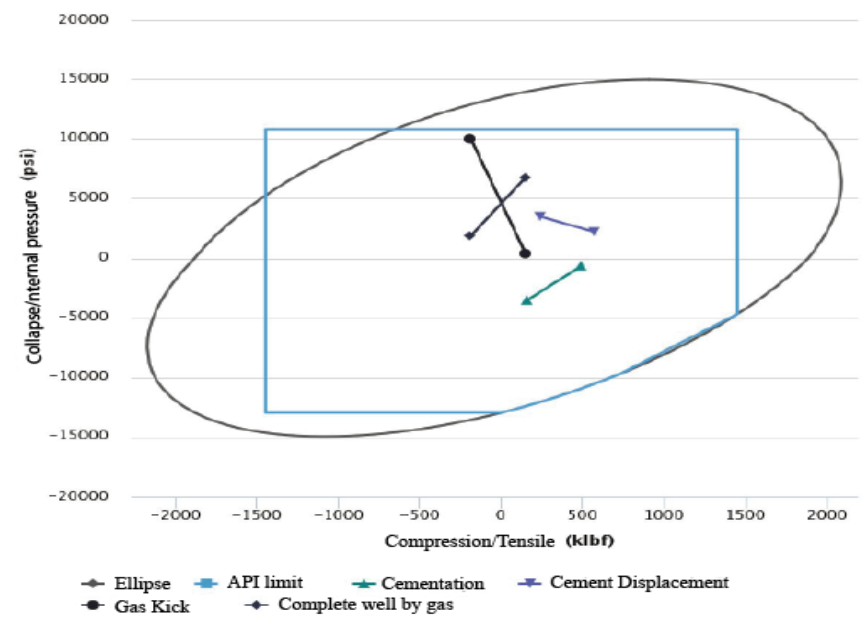

Figure 7. Triaxial results for the case of analysis with V150 in phase 3.

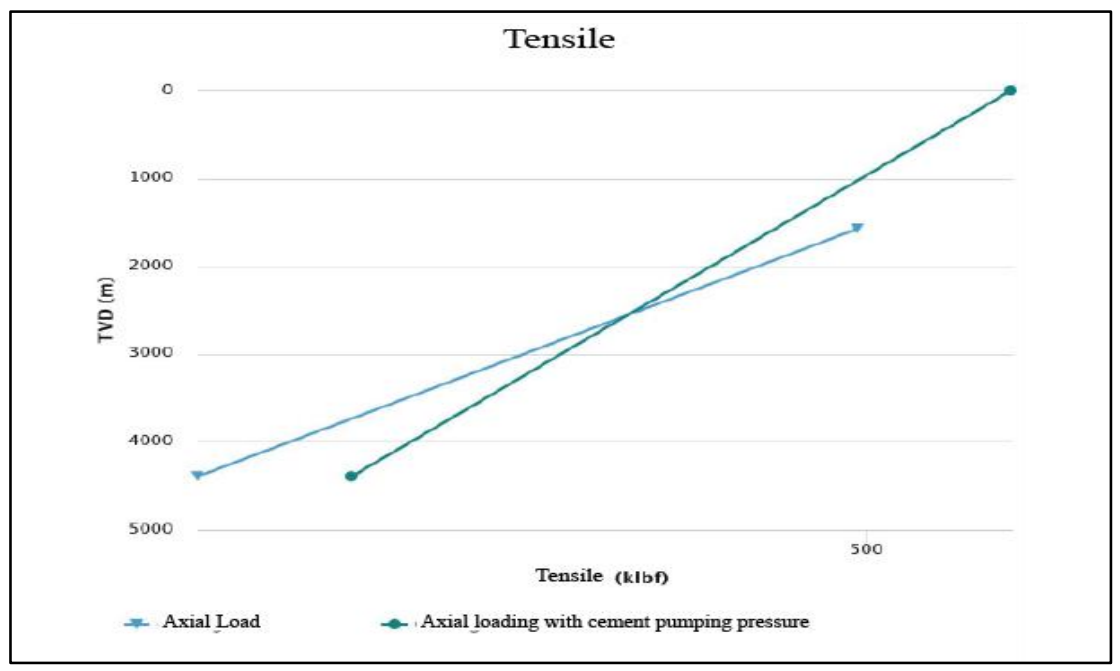

Figure 8. Axial loading in phase 3 for a V150 pipe.

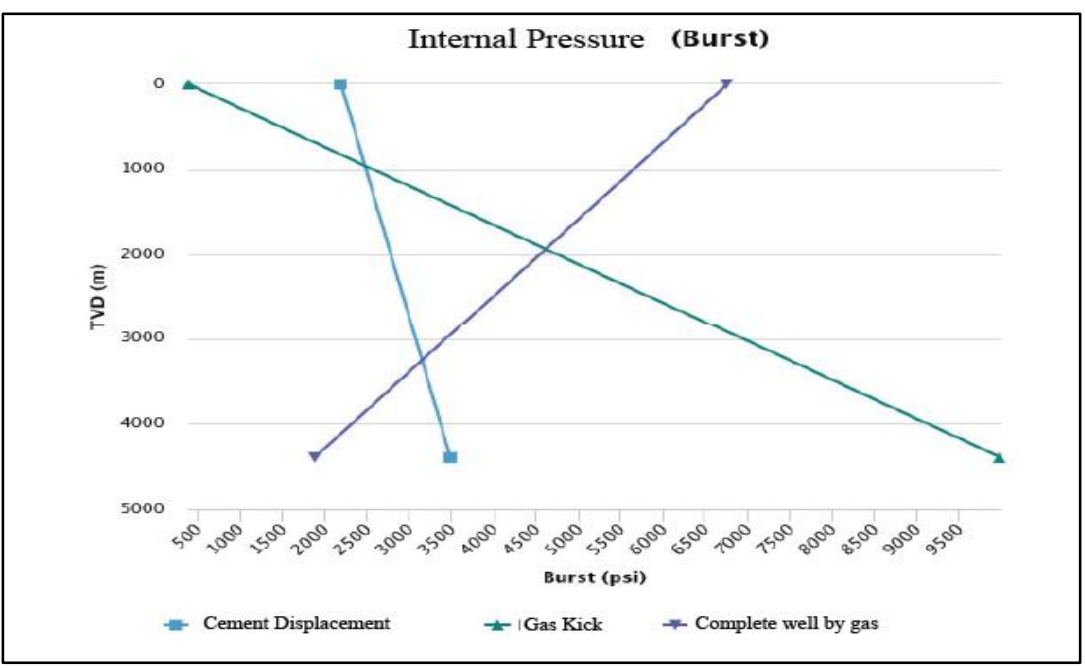

Figure 9. Internal pressure charging on phase 3 for V150. 
By comparing the maximum values of tension and internal pressure (Figures 8 and 9) to which the pipe is subjected with its axial strength and internal pressure, respectively, one can observe that there is no fault in the pipe.

Thus, it can be stated that the V150 pipe is capable of resisting the necessary stresses, preventing failure and possible loss of structural integrity of the well.

\section{CONCLUSIONS}

From this study, it is possible to establish the importance of cementation in the face of some exposed scenarios, as well as the liner-simulation integrity. Kicks are one of the most frequent operational problems in oil wells and can lead to blowouts and major catastrophes when not controlled.

In this context, the present study evaluated the casing columns when submitted to a gas kick, also considering the effects of the cementing operation. For this analysis, it was used the criterion of mechanical strength of von Misses and API envelope.

Through the analysis between the resistances returned by SAEP, it is possible to verify the possibility of failure of the tubes for each project scenario, which is extremely important for the sizing of columns, to obtain the best performance of structures, without unnecessary costs from the use of pipes of much higher mechanical resistance than the necessary.

It is essential to develop proper casing and drilling column projects, capable of resisting the most adverse situations, especially the most common critical scenarios during drilling, such as the presence of kick and problems associated with the cementing process.

\section{REFERENCES}

Adams, N. J.; Drilling Engineering. A complete well planning approach. Tulsa: Penn Well Publishing Company, 1985.
API ISO 10400. Technical report on equations and calculations for casing, tubing, and line pipe used as casing or tubing; and performance properties tables for casing and tubing. Washington: American Petroleum Institute, 2007.

API TR 5C3. Technical Report on Equations and Calculations for Casing, Tubing, and Line. Pipe Used as Casing or Tubing; and Performance Properties Tables for Casing and Tubing. 1st. Ed. Washington, D.C., 2008.

Baker, J.; Ferraioli, P. Well Construction Process Modeling and Simulation. Offshore Technology Conference, 2018. https://doi.org/10.4043/28816-MS

Bearden, W. G.; Lane, R. D. Engineered cementing operations to eliminate WOC time. Drilling and Production Practice, API-61-017, 1961.

Bourgoyne Jr., A. T.; Milheim, K. K.; Chenevert, M. E.; Young Jr., F. S. Applied Drilling Engineering. $2^{\text {nd }}$ Edition. Texas: Society of Petroleum Engineers, 1991.

Correia, J. P. A.; Santos, J. P. L. Avaliação numérica da integridade estrutural de revestimento de poços de petróleo em zonas de alta pressão e alta temperatura e áreas de rochas salinas. Holos, v. 1, p. 292-305, 2017.

https://doi.org/10.15628/holos.2017.5178

Costa, J. C. H. Sistema de aplicações de engenharia de petróleo (SAEP): MÓDULO POÇO. Maceió: Universidade Federal de Alagoas, 2016.

Enayatpour, S.; van Oort, E. Advanced modeling of cement displacement complexities. Fort Worth: SPE/IADC Drilling Conference and Exhibition, SPE184702-MS, The Hague, Netherlands, 2017. https://doi.org/10.2118/184702-MS

Holt, C.; Lahoti, N.; Fortier, V. Dynamic cementation: A solution to well integrity problems. SPE/IADC Drilling Conference and Exhibition, SPE163459-MS, Amsterdam, Netherlands, 2013. https://doi.org/10.2118/163459-MS

Mendes, J. R. P.; Fonseca, T. C.; Miura, K. An integrity analysis approach for development wells. Journal of the Brazilian Society of Mechanical Sciences and Engineering, v. 38(4), p. 1239-1248, 2016. https://doi.org/10.1007/s40430-015-0479-1 
Oliveira, F. F.; Sodré, C. H.; Marinho, J. L. G. Flow parameter evaluation during the occurrence of a gas kick in a petroleum drilling using turbulence models: A numerical study. Brazilian Journal of Petroleum and Gas, v. 10(3), 2016. https://doi.org/10.5419/bjpg2016-0012

Pelipenko, S.; Frigaard, I. Mud removal and cement placement during primary cementing of an oil well - Part 2; steady-state displacements. Journal of Engineering Mathematics, v. 48(1), p. 126, 2004.

https://doi.org/10.1023/B:ENGI.00000094999.63859.f0

Rogers, H.; Heathman, J. Cementing casing equipment: Proper selection vital to success. Offshore Technology Conference, OTC-17083-MS, Houston, Texas, 2005. https://doi.org/10.4043/17083$\underline{\mathrm{MS}}$

Salmazo, E.; Mendes, J. R. P.; Miura, K. The influence of salt domes in drilling well activities. Brazilian Journal of Petroleum and Gas, v. 7(2), 2013. https://doi.org/10.5419/bjpg2013-0004
Silva, T. V. Desenvolvimento de sistema para análise de casos de carregamento em colunas de perfuração baseado em interface web. Trabalho de Conclusão de Curso (Graduação em Engenharia de Petróleo), Universidade Federal de Alagoas, 2017.

Thomas, J. E., Fundamentos de Engenharia de petróleo. Rio de Janeiro: Ed. Interciência, 2004.

Thompson, J. L.; Callison, J. D. Recent development in oil well cementing. Venezuelan Annual Meeting, SPE-1417-G, Venezuela, Caracas, 1959. https://doi.org/10.2523/1417-G

Vitorino, A. F. R. A., Machado, L. F.; Silva, T. V.; Araújo, J. P. N.; Gouveia, L. P.; Santos, J. P. L. Pressure test after wait on cement (WOC): Analysis in oil well casing design. Brazilian Journal of Petroleum and Gas, v. 12(4), p. 241-250, 2018. https://doi.org/10.5419/bjpg2018-0022 